\title{
Medication adherence has an impact on disease activity in rheumatoid arthritis: a systematic review and meta-analysis
}

This article was published in the following Dove Press journal:

Patient Preference and Adherence

4 August 2017

Number of times this article has been viewed

Lin $\mathrm{Li}^{1,2, *}$

Yafei Cui ${ }^{2}, *$

Rulan Yin ${ }^{3, *}$

Shengnan Chen ${ }^{2}$

Qian Zhao ${ }^{2}$

Haoyang Chen'

Biyu Shen'

'Department of Nursing, The Second Affiliated Hospital of Nantong

University, Nantong, China; ${ }^{2}$ School of Nursing, Nantong University, Nantong, China; ${ }^{3}$ Department of Emergency ICU, The First Affiliated Hospital of Soochow University, Suzhou, China

*Lin Li, Yafei Cui, Rulan Yin contributed equally to this work
Correspondence: Biyu Shen Department of Nursing, The Second Affiliated Hospital of Nantong University, 6th Haier Lane Road, 226001

Nantong, China

Tel +86 I38 62937317

Email shenbiyu@126.com
Objective: Disease activity of rheumatoid arthritis (RA) patients was often measured by the 28-joint count disease activity score (DAS-28), which consists of 28 swollen and tender joint counts, patient's assessment of disease activity (visual analog scale [VAS]) and erythrocyte sedimentation rate. C-reactive protein was also used to measure disease activity in RA patients. The aim was to explore the impact of medication adherence on disease activity in patients with RA.

Methods: A systematic search was performed in major electronic databases (PubMed, Web of Science, the Cochrane Library, CNKI, VIP and Wan fang) to identify studies reporting medication adherence and disease activity in RA patients. Results were expressed as mean difference (MD) and 95\% CI.

Results: A total of seven identified studies matched the inclusion criteria, reporting on a total of 1,963 adult RA patients in the analysis. The total score of DAS-28 was significantly lower in adherent patients than in nonadherent subjects ( $\mathrm{MD}=-0.42,95 \% \mathrm{CI}[-0.80,-0.03], P=0.03)$. Similarly, a significant difference was observed between medication adherent and nonadherent groups in erythrocyte sedimentation rate (MD $=-7.39,95 \% \mathrm{CI}[-11.69,-3.08], P<0.01)$ and tender joint count $(\mathrm{MD}=-1.29,95 \% \mathrm{CI}[-2.51,-0.06], P=0.04)$. Interestingly, the results of the meta-analysis showed no significant difference between medication adherent and nonadherent patients in swollen joint count ( $\mathrm{MD}=-0.16,95 \% \mathrm{CI}[-2.13,1.80], P=0.87)$, visual analog scale $(\mathrm{MD}=1.41,95 \% \mathrm{CI}[-3.68,6.50], P=0.59)$ and $\mathrm{C}$-reactive protein $(\mathrm{MD}=0.35,95 \% \mathrm{CI}$ $[-0.64,1.34], P=0.49)$.

Conclusion: The study suggests that RA patients with higher medication adherence tended to have lower disease activity.

Keywords: rheumatoid arthritis, medication adherence, disease activity, meta-analysis

\section{Background}

Rheumatoid arthritis (RA) is a chronic autoimmune inflammatory disease possessing articular and extra-articular features. ${ }^{1}$ Its prevalence of $0.5 \%-1 \%$ in the general population makes it the most common chronic inflammatory condition. ${ }^{2}$ Incompletely controlled RA results in progressive irreversible joint damage, functional impairment, morbidity and increased mortality due to cardiovascular complications, ${ }^{1}$ and it is associated with marginal joint erosions, generalized bone loss or osteoporosis. ${ }^{3}$ Pharmacologic therapies in RA patients include conventional (synthetic) diseasemodifying antirheumatic drugs (csDMARDs; such as methotrexate [MTX]), biologic disease-modifying antirheumatic drugs (bDMARDs) and bisphosphonates; both therapies are effective in treating the symptoms and signs of RA and for halting the 
progression of structural damage. ${ }^{3,4}$ Treatment with diseasemodifying antirheumatic drugs (DMARDs) and bDMARDs prevents the disease from becoming worse and improves long-term functional outcome. ${ }^{5}$ Bisphosphonates can increase bone mineral density and reduce fractures as well. ${ }^{3}$ Adherence to medication therapy is important to reach the desired treatment outcome and for the management of RA, especially at the start of treatment. ${ }^{6}$

Adherence to a medication regimen is "the extent to which patients take medications as prescribed by their health care providers". ${ }^{7}$ In RA, medication adherence is highly variable and typically suboptimal, with reports of adherence to conventional DMARDs ranging from 22\% (underuse) to $107 \%$ (overuse). ${ }^{8}$ Poor adherence with therapy affects $20 \%-70 \%$ of patients with RA, sometimes during their follow-up. ${ }^{9}$ The consequences of nonadherence will not only affect the patient's disease activity, but also the rheumatologist's treatment decisions, and lead to higher health care costs. ${ }^{10}$ At the individual level, large differences in treatment response, as often measured with the 28-joint count disease activity score (DAS-28), which consists of 28 swollen and tender joint counts (SJC and TJC), patient's assessment of disease activity (visual analog scale [VAS]) and erythrocyte sedimentation rate (ESR), are observed. ${ }^{6}$ Instead of ESR, $\mathrm{C}$-reactive protein (CRP) as another important indicator was also used to measure disease activity in RA patients. ${ }^{11-13}$ The most desirable target measure of disease activity is remission, which signifies a condition of negligible or no inflammatory activity, absolute arrest of structural joint damage and the optimum achievable reversal of disability. ${ }^{14}$

Some studies ${ }^{3,15-17}$ suggested that higher medication adherence with RA exhibits achievement of lower disease activity during treatment with drugs. However, these results were challenged and not confirmed by other studies, ${ }^{18-20}$ and no systematic review was conducted to quantify the association of medication adherence and disease activity in RA using meta-analysis techniques. The objectives of this systematic review were: 1) to find the relationship between medication adherence and disease activity among adult RA patients; 2) to provide a summary of the methods used to define medication adherence and disease activity in RA, and 3) to summarize supportive measures to enhance medication adherence.

\section{Materials and methods}

The meta-analysis was reported in accordance with the recommendations of the Preferred Reporting Items for Systemic Review and Meta-Analyses and the Meta-analysis of Observational Studies in Epidemiology as closely as possible. ${ }^{21,22}$ A protocol for this review was prospectively developed, detailing the specific objectives, the criteria for study selection, the approach to assessment of study quality, the outcomes and the statistical methods.

\section{Search strategy}

We conducted a systematic search on the English language databases of PubMed and Web of Science, Cochrane Library and Chinese databases of the CNKI Scholar, VIP and WanFang (from inception to February 2017) for investigations regarding medication adherence and disease activity in RA. Different search strategies were combined and they are as follows: English language articles for the combinations of the following terms: "rheumatoid arthritis", "RA" and "adherence", "compliance". For the Chinese articles, free-text terms were used, including the Chinese translations of terms meaning adherence and disease activity and RA. The search strategy was developed without publication year restriction. In addition, the reference lists of all retrieved articles were manually reviewed. In case of missing data, we corresponded with the authors for further information if we encountered articles that just provided one part of the DAS-28 assessment scale. Two independent authors (LL and YC) analyzed each article and performed the data extraction independently. In case of disagreement, a third investigator was consulted (RY).

\section{Inclusion and exclusion criteria}

The study inclusion criteria were: 1) studies with a crosssectional design, baseline cross-sectional data from a longitudinal study or baseline cross-sectional data from a trial, before group allocation; 2) studies that used validated methods (clinical interviews or self-report instruments) to assess medication adherence and disease activity; 3 ) the outcome variables had to include at least one of the following variables: total score of DAS-28, ESR, SJC, TJC, VAS and/or CRP; 4) treatment medication included csDMARDs (such as MTX) or bDMARDs or bisphosphonates, and 5) the sample size was no less than 60 .

The exclusion criteria were: 1) conference abstracts, case reports, comments, letters to editor, review articles, familybased studies, studies in languages other than English and Chinese, and papers not dealing with RA patients, and 2) studies without available data.

\section{Data extraction and quality assessment}

All articles were retrieved and assessed independently by two reviewers who extracted data including authors, publication date, country of origin, characteristics of the study population including diagnostic criteria for RA, number of 
subjects, type of study and other details of adjustment. From each study, data regarding sample size, major clinical and demographic variables and data about adherence and disease activity achievement were extracted. To exclude the risk of data overlap, original databases were analyzed for studies performed in the same institutions. The methodological quality of each study included in this meta-analysis was assessed using a modified version of the Newcastle-Ottawa Scale (NOS), which was applied by including relevant items from NOS case-control, NOS cohort and the modified NOS cross-sectional designs. ${ }^{23}$ Baseline cross-sectional data from a trial could also be extracted. Studies were judged to be at low risk of bias ( $\geq 3$ points) or high risk of bias ( $<3$ points); modified Newcastle Ottawa Scale (M-NOS) evaluated primary study quality in terms of several domains: sample representativeness and size, comparability between respondents and nonrespondents, ascertainment of depressive symptoms and statistical quality.

\section{Outcome measures}

Medication adherence was defined in eight different ways, as described in Table S1. The outcomes were the total score of DAS-28, SJC, TJC, VAS, ESR and CRP.

\section{Statistical analysis and risk of bias assessment}

The correlation of patient's medication adherence and disease activity was evaluated using Review Manager meta-analysis software (version 5.3; Cochrane Collaboration, Copenhagen, Denmark). The mean difference (MD) and 95\% CI were calculated for continuous data. A fixed-effect model was applied to combine these MDs to get an overall MD, also known as an effect estimate. In order to be as conservative as possible, the random-effect method was used to take into account the variability among included studies. Heterogeneity of effects across studies was assessed using the $\chi^{2}$ test statistic and quantified by $l^{2}$, which represented the percentage of total variation across studies that was attributable to heterogeneity rather than chance. In detail, $I^{2}$ values of $0 \%$ indicate no heterogeneity, $25 \%$ low heterogeneity, $25 \%-50 \%$ moderate heterogeneity and $50 \%$ high heterogeneity. ${ }^{24} \mathrm{~A} z$ score was adopted to assess the overall effect, with significance set at $P<0.05$. Publication bias was assessed with a visual inspection of a funnel plot and the Egger's bias value.

\section{Subgroup analyses}

Subgroup analyses were supposed to be performed based on ethnicity (Caucasian, Asian and African American), study quality (NOS $\geq 3$, NOS $<3$ ), sample size ( $>100$ cases, $\leq 100$ cases) and geographic region (West Asia, East Asia, North America, Africa and Europe). ${ }^{25}$ For a meta-analysis study, the statistical power might reduce with the decrease in sample size and number of studies. Jeffrey and Valentine suggested that the minimal number of studies in meta-analysis should be two. ${ }^{26}$ Thus, we undertook subgroup analyses in only those subgroups with more than two studies.

\section{Sensitivity analyses}

Sensitivity analyses were conducted by sequentially omitting one individual study at a time, to identify the influence of each study on the pooled odds ratio and determine whether the assumptions or decisions had a major effect on the results of the review and the results were stable and reliable.

\section{Results}

As reported in Figure 1, 588 of the 627 retrieved studies were excluded because of duplication, reviews, case reports, small sample and data form, or not relevant after scanning the title and/or the abstract. After full-length paper evaluation, another 32 studies were excluded because they only reported one part of medication adherence and disease activity, so that no relation can be determined between medication adherence and disease activity. Finally, seven studies ${ }^{3,15-20}$ comprising a total of 1,963 patients were included in the meta-analysis.

\section{Study characteristics}

A summary of the characteristics of the included studies is shown in Table 1. Briefly, seven studies which were conducted among different countries, that is, the Netherlands, ${ }^{19}$ Mexico, ${ }^{16,18}$ USA, ${ }^{3,17}$ Pakistan ${ }^{15}$ and China, ${ }^{20}$ were published between 2004 and 2016. Based on the geographic region, two of these studies were conducted in Latin America, ${ }^{16,18}$ two in North America, ${ }^{3,17}$ one in south Asia, ${ }^{15}$ one in Europe $^{19}$ and one in Asia. ${ }^{20}$ Five studies had large sample size ( $>100$ cases) $)^{3,17-20}$ and two were of small sample size ( $\leq 100$ cases). ${ }^{15,16}$ When evaluated by M-NOS criteria, out of 5 possible points, four received 4 points, one received 3 points, one received 2 points and one received 1 point (Table 2). The details of the assessment of the individual studies are shown in Box S1.

\section{Effectiveness of adherence}

There were seven studies that compared disease activity between adherent and nonadherent patients in RA. Results of these studies involved participants included by the 


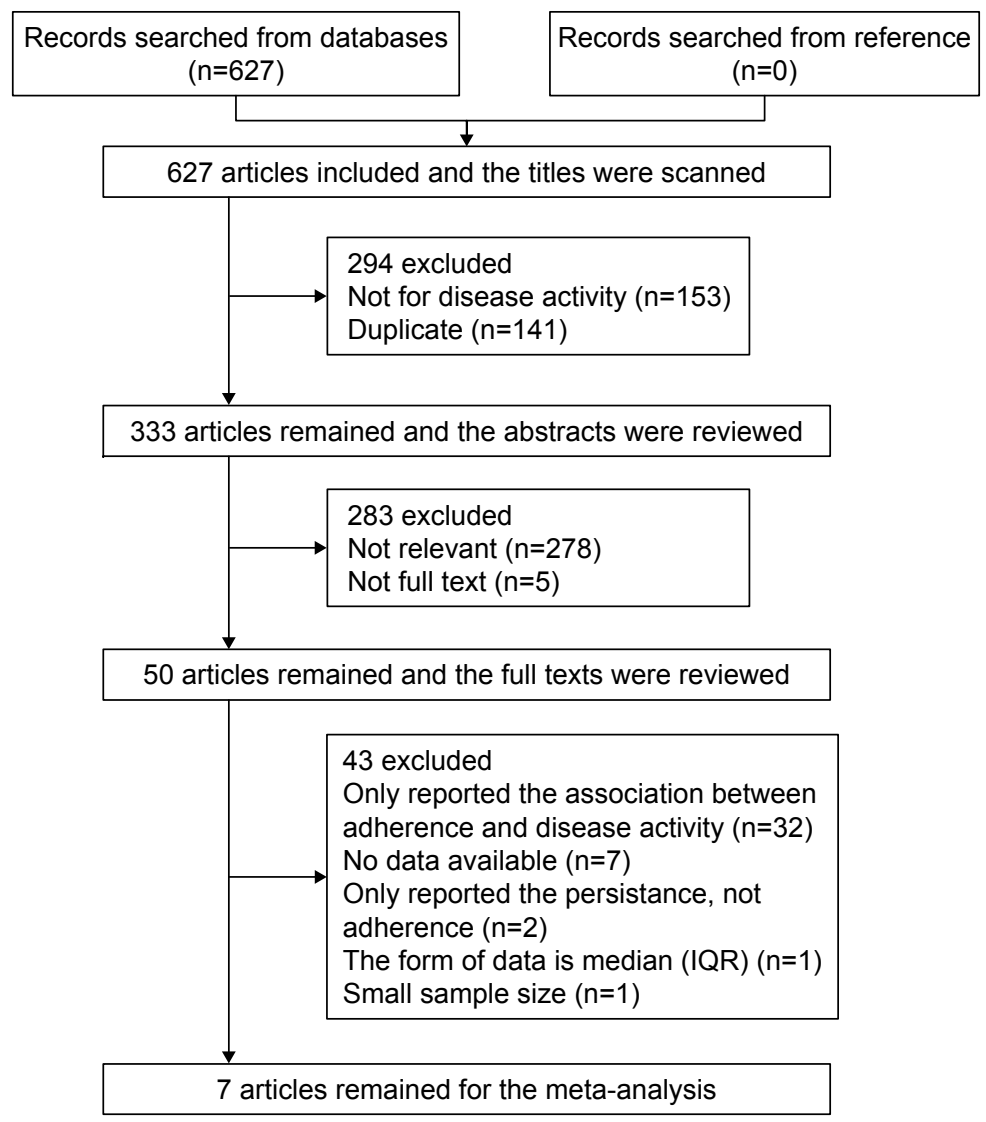

Figure I Flow chart showing selection of studies for inclusion in this meta-analysis. Abbreviation: IQR, interquartile range.

researchers in their analyses, many of whom excluded some participants for many reasons, including uncollected data. Statistical heterogeneity was tested for each outcome. Table 3 provides a summary of the results of the overall meta-analysis for each of the outcomes.

\section{The total score of DAS-28 for RA patients}

There were six studies involving 1,754 patients that compared disease activity in RA patients with medication adherence or nonadherence. Heterogeneity analyses revealed substantial heterogeneity across studies $(P<0.00001$, $I^{2}=87 \%$ ), and therefore, a random-effects model was used. The results of the meta-analysis revealed that a significant difference was observed between adherent and nonadherent groups $(\mathrm{MD}=-0.42,95 \% \mathrm{CI}[-0.80,-0.03], P=0.03$; Figure 2A).

\section{ESR for RA patients}

Three studies reported ESR involving 670 participants; 476 patients were medication adherent and 194 were nonadherent. A fixed-effects model was used because the heterogeneity test showed an $I^{2}$ of $24 \%$ among the studies $(P=0.27)$. A significant difference was observed between adherent and nonadherent groups $(\mathrm{MD}=-7.39,95 \% \mathrm{CI}$ $[-11.69,-3.08], P=0.0008$; Figure 2B).

\section{SJC for RA patients}

Two studies reported SJC involving 577 participants; 429 patients were medication adherent and 148 were nonadherent. Heterogeneity analyses revealed substantial heterogeneity across studies $\left(P=0.04, I^{2}=76 \%\right)$, and therefore, a random-effects model was used. The results of the metaanalysis indicated that no significant difference was observed between adherent and nonadherent patients (MD $=-0.16$, $95 \%$ CI $[-2.13,1.80], P=0.87$; Figure $2 \mathrm{C}$ ).

\section{TJC for RA patients}

Two studies reported SJC involving 577 participants; 429 patients were medication adherent and 148 were nonadherent. A fixed-effects model was used because the heterogeneity test showed an $I^{2}$ of $23 \%$ among the studies $(P=0.25)$. 


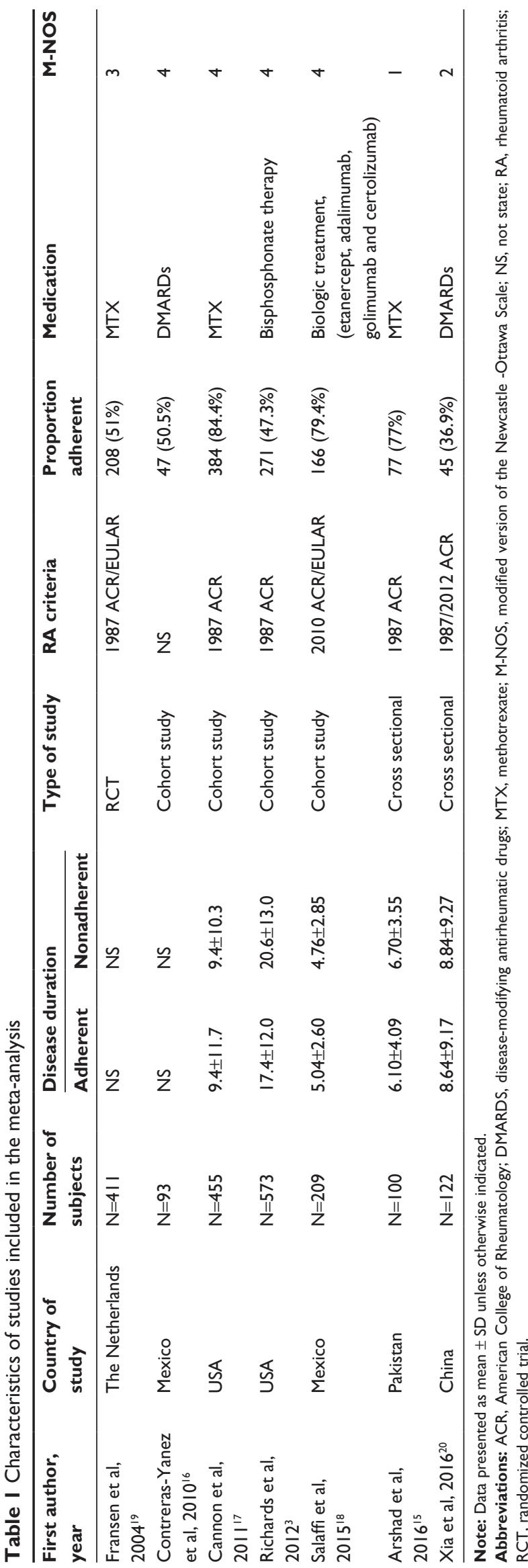

A significant difference was observed between adherent and nonadherent groups (MD $=-1.29,95 \%$ CI $[-2.51,-0.06]$, $P=0.04$; Figure 2D).

\section{VAS for RA patients}

A fixed-effects model was used because the heterogeneity test showed an $I^{2}$ of $0 \%$ among the studies $(P=0.70)$. The results of the meta-analysis found that there was no significant difference between adherent and nonadherent patients (MD $=1.41,95 \%$ CI $[-3.68,6.50], P=0.59$; Figure 2E).

\section{CRP for RA patients}

Four studies reported CRP involving 879 participants; 642 patients were medication adherent and 237 were nonadherent. Heterogeneity analyses revealed substantial heterogeneity across studies $\left(P=0.00008, I^{2}=82 \%\right)$, and therefore, a random-effects model was used. The results of the meta-analysis indicated that no significant difference was observed between adherent and nonadherent patients (MD $=0.35,95 \%$ CI $[-0.64,1.34], P=0.49$; Figure 2F).

\section{Sensitivity analyses and publication bias}

Sensitivity analysis was performed by sequentially omitting one study at a time to infer the influence of each study on the overall meta-analysis. For all comparisons between adherent and nonadherent patients, the omission of any study made no significant difference, indicating the stability of our meta-analysis. Assessment of publication bias indicated no significant publication bias, according to the Egger's test (Egger: $t=-1.88, P=0.133$ ).

\section{Subgroup analyses}

The subgroup analyses were conducted according to the country of origin, sample size, publication year, study quality and measurements of medication adherence. The results of the meta-analysis indicated that the sample size may be the source of heterogeneity. The subgroup analysis for the country of origin, publication year, study quality and measurements of medication adherence showed no clear patterns (as given in Figure S1).

\section{Discussion}

The objective of this systematic review was to investigate the association of medication adherence and disease activity among RA patients. Nowadays, medication adherence is a major contributor to treatment outcomes. However, inadequate medication adherence is common in clinical practice; especially in RA, rates of adherence to DMARDs 
Table 2 Quality assessment of the included studies measured by M-NOS

\begin{tabular}{|c|c|c|c|c|c|c|}
\hline Study ID & Representativeness & Size & Comparability & Outcome & Statistics & Total \\
\hline Fransen et al ${ }^{19}$ & I & I & 1 & 0 & 0 & 3 \\
\hline Contreras-Yanez et al ${ }^{16}$ & I & 0 & 1 & I & I & 4 \\
\hline Cannon et $\mathrm{al}^{17}$ & I & I & 0 & I & I & 4 \\
\hline Richards et $\mathrm{al}^{3}$ & I & I & 0 & I & I & 4 \\
\hline Salaffi et $\mathrm{al}^{18}$ & 0 & I & I & I & I & 4 \\
\hline Arshad et al ${ }^{15}$ & 0 & 0 & 0 & 0 & I & I \\
\hline$X i a$ et $\mathrm{al}^{20}$ & 0 & 0 & 0 & I & I & 2 \\
\hline
\end{tabular}

Notes: Low risk of bias ( $\geq 3$ points); high risk of bias ( $<3$ points).

Abbreviation: M-NOS, modified Newcastle Ottawa Scale.

are highly variable, ranging from $30 \%$ to $107 \%$ for conventional DMARDs and from $41 \%$ to $90 \%$ for biologic agents. ${ }^{27}$ This variability may be because of the different measurement methods used, such as pharmacy data, electronic monitoring, self-report and physician report. ${ }^{8}$

To the best of our knowledge, the current systematic review and meta-analysis of seven studies involving 1,963 participants is the first to investigate a relationship between medication adherence and disease activity in RA patients. Adherence is believed to be the main contributor to treatment outcome in many clinical settings. ${ }^{28}$ Likewise, nonadherence to medications generally worsens outcomes of treatments, leading to increased risk of adverse medical events, more consultations with physicians, higher rates of hospitalization and increased health care costs. ${ }^{18}$ In RA, the relationship between medication adherence and treatment outcomes such as disease activity has not been widely explored. Some studies reported that nonadherence was associated with a poorer disease activity outcome; $6,29,30$ however, another study found that adherence was not associated with improvements in physical function. ${ }^{17}$ Nevertheless, in $80 \%-90 \%$ of the patients per visit, rheumatologists still thought DAS-28, the most commonly used method to measure disease activity, could adequately represent the degree of disease activity in RA patients. ${ }^{31}$
In this meta-analysis, we evaluated the impact of medication adherence on disease activity in patients with RA. Interestingly, the results of the meta-analysis indicated that there was no significant difference between medication adherent and nonadherent patients in SJC, VAS and CRP. The reason for these outcomes may be explained by several factors, such as the small number of studies included in the analysis, which may limit the power of our calculations, type of included study, different measures used across the studies and limitations of insufficient data provided. Interestingly, Lee and $\operatorname{Tan}^{32}$ reported that drug noncompliance was not a major problem in treatment of RA, because $92 \%$ of patients took their prescribed antirheumatic medication either all or most of the time, with noncompliance being correlated with less severe disease activity and lessening of symptoms.

It is important to better know patients' adherence patterns and their behavior, as well as to provide supportive measures to enhance the response to a prescribed drug therapy. More recently, a qualitative study found that all patients highlighted that good communication with health professionals, health professional support and better explanation of the risks of RA to their health would all promote better medication adherence. ${ }^{33}$ Salaffi et al concluded that a number of factors related to improved medication adherence,

Table 3 Meta-analysis of outcome measures

\begin{tabular}{|c|c|c|c|c|c|c|c|c|}
\hline \multirow[t]{2}{*}{ Outcome } & \multirow[t]{2}{*}{$\begin{array}{l}\text { Number of } \\
\text { studies }\end{array}$} & \multirow{2}{*}{$\begin{array}{l}\text { Sample size } \\
\text { (adherencel } \\
\text { nonadherence) }\end{array}$} & \multicolumn{2}{|c|}{$\begin{array}{l}\text { Heterogeneity } \\
\text { test }\end{array}$} & \multirow[t]{2}{*}{$\begin{array}{l}\text { Model } \\
\text { selection }\end{array}$} & \multirow[t]{2}{*}{ MD or SMD } & \multirow[t]{2}{*}{$95 \% \mathrm{Cl}$} & \multirow[t]{2}{*}{$P$-value } \\
\hline & & & $P$-value & $I^{2}(\%)$ & & & & \\
\hline DAS-28 & 6 & $|, 033 / 72|$ & $<0.01$ & 87 & Random & -0.42 & $-0.80,-0.03$ & 0.03 \\
\hline ESR & 3 & $476 / 194$ & 0.27 & 24 & Fix & -7.39 & $-11.69,-3.08$ & 0.0008 \\
\hline SJC & 2 & $429 / 148$ & 0.04 & 76 & Random & -0.37 & $-1.30,0.56$ & 0.87 \\
\hline TJC & 2 & $429 / 148$ & 0.25 & 23 & Fix & -1.29 & $-2.5 \mathrm{I},-0.06$ & 0.04 \\
\hline VAS & 2 & $429 / 148$ & 0.70 & 0 & Fix & 1.41 & $-3.68,6.50$ & 0.59 \\
\hline CRP & 4 & $642 / 237$ & $<0.01$ & 82 & Random & 0.35 & $-0.64,1.34$ & 0.49 \\
\hline
\end{tabular}

Abbreviations: CRP, C-reactive protein; DAS-28, the 28-joint count disease activity score; ESR, erythrocyte sedimentation rate; MD, mean difference; SJC, 28 swollen joint counts; TJC, 28 tender joint counts; SMD, standard mean difference; VAS, visual analog scale. 


\begin{tabular}{|c|c|c|c|c|c|c|c|c|}
\hline \multirow{2}{*}{$\begin{array}{l}\text { Study or } \\
\text { subgroup }\end{array}$} & \multicolumn{2}{|c|}{ Adherence } & \multirow[b]{2}{*}{ Total } & \multicolumn{3}{|c|}{ Nonadherence } & \multirow{2}{*}{$\begin{array}{l}\text { Weight } \\
\text { (\%) }\end{array}$} & \multirow{2}{*}{$\begin{array}{l}\text { Mean difference IV, } \\
\text { random, } 95 \% \mathrm{Cl}\end{array}$} \\
\hline & Mean & SD & & Mean & SD & Total & & \\
\hline Ars & 4.38 & 1. & 77 & 5.32 & 0.92 & 23 & 16.2 & -0.9 \\
\hline & & 1. & & & 15 & & & .07) \\
\hline Franse & 5 & 1.1 & 208 & 4.8 & 1.12 & 203 & 19.5 & $0.20(-0.01,0.41)$ \\
\hline et $\mathrm{al}^{3}$ & 3.63 & 1.13 & 272 & 3.84 & 1.21 & 302 & 19.7 & $0,-0.0$ \\
\hline & 3.73 & 1.55 & 45 & 3.85 & 1.5 & 77 & 14.4 & $8,0.44)$ \\
\hline Contreras-Yanez et a $\left.\right|^{16}$ & 3.6 & 1.3 & 47 & 5.1 & 1.9 & 46 & 12.9 & $-1.50(-2.16,-0.8$ \\
\hline Total $(95 \% \mathrm{Cl})$ & & & 1,033 & & & 722 & 100 & $-0.42(-0.80,-0.0$ \\
\hline
\end{tabular}

Heterogeneity: $\tau^{2}=0.19 ; \chi^{2}=38.81, d f=5(P<0.00001) ; l^{2}=87 \%$

Test for overall effect: $Z=2.12(P=0.03)$

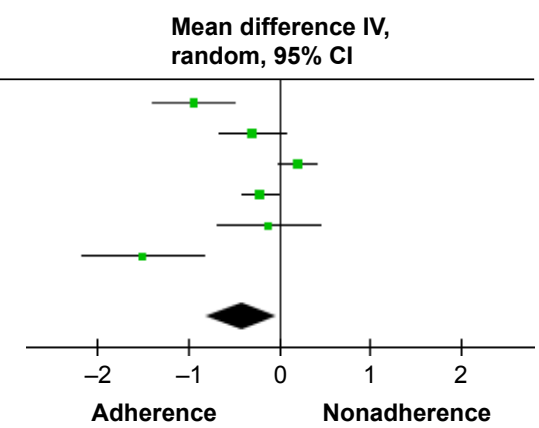

\begin{tabular}{|c|c|c|c|c|c|c|c|c|}
\hline $\begin{array}{l}\text { Study or } \\
\text { subgroup }\end{array}$ & $\begin{array}{l}\text { Adhere } \\
\text { Mean }\end{array}$ & $\begin{array}{l}\text { ence } \\
\text { SD }\end{array}$ & Total & $\begin{array}{l}\text { Nonac } \\
\text { Mean }\end{array}$ & $\begin{array}{l}\text { Iherenc } \\
\text { SD }\end{array}$ & e & $\begin{array}{l}\text { Weight } \\
(\%)\end{array}$ & $\begin{array}{l}\text { Mean difference IV, } \\
\text { fixed, } 95 \% \mathrm{Cl}\end{array}$ \\
\hline Cannon et al ${ }^{17}$ & 24 & 18 & 384 & 29 & 24 & 71 & 53.9 & $-5.00(-10.87,0.87)$ \\
\hline Xia et $\mathrm{al}^{20}$ & 24.42 & 24.86 & 45 & 30.52 & 27.7 & 77 & 20.4 & $-6.10(-15.64,3.44)$ \\
\hline Contreras-Yanez et al $\left.\right|^{16}$ & 24.1 & 17.4 & 47 & 37.5 & 23.8 & 46 & 25.7 & $-13.40(-21.89,-4.91)$ \\
\hline Total $(95 \% \mathrm{Cl})$ & & & 476 & & & 194 & 100 & $-7.39(-11.69,-3.08)$ \\
\hline
\end{tabular}

Heterogeneity: $\chi^{2}=2.63, d f=2(P=0.27) ; l^{2}=24 \%$

Test for overall effect: $Z=3.36(P=0.0008)$

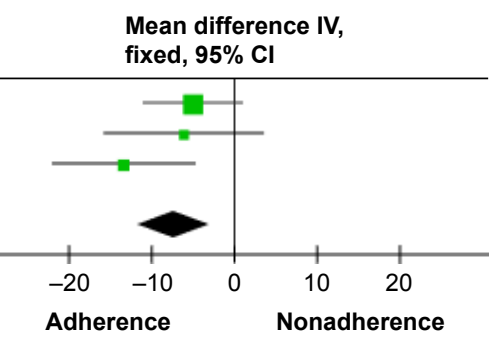

\begin{tabular}{|c|c|c|c|c|c|c|c|c|c|c|c|}
\hline \multirow{2}{*}{$\begin{array}{l}\begin{array}{l}\text { Study or } \\
\text { subgroup }\end{array} \\
\text { Cannon et al }{ }^{17}\end{array}$} & \multicolumn{2}{|c|}{$\begin{array}{l}\text { Adherence } \\
\text { Mean SD }\end{array}$} & Total & $\begin{array}{l}\text { Nonadt } \\
\text { Mean }\end{array}$ & $\begin{array}{l}\text { herence } \\
\text { SD }\end{array}$ & Total & $\begin{array}{l}\text { Weight } \\
(\%)\end{array}$ & $\begin{array}{l}\text { Mean difference IV, } \\
\text { random, } 95 \% \mathrm{Cl}\end{array}$ & & $\begin{array}{l}\text { Mean difference IV, } \\
\text { random, } 95 \% \mathrm{Cl}\end{array}$ & \\
\hline & 3.2 & 3.3 & 384 & 4.3 & 4.8 & 71 & 53.3 & $-1.10(-2.26,0.06)$ & & & \\
\hline Xia et $a^{20}$ & 3.27 & 4.6 & 45 & 2.36 & 3.38 & 77 & 46.7 & $0.91(-0.63,2.45)$ & & & \\
\hline Total $(95 \% \mathrm{CI})$ & & & 429 & & & 148 & 100 & $-0.16(-2.13,1.80)$ & & & \\
\hline \multicolumn{9}{|c|}{$\begin{array}{l}\text { Heterogeneity: } \tau^{2}=1.53 ; \chi^{2}=4.16, d f=1(P=0.04) ; l^{2}=76 \% \\
\text { Test for overall effect: } Z=0.16(P=0.87)\end{array}$} & -10 & -5 & 10 \\
\hline \multicolumn{9}{|c|}{ Test for overall effect: $Z=0.16(P=0.87)$} & \multicolumn{2}{|c|}{ Adherence } & ice \\
\hline
\end{tabular}

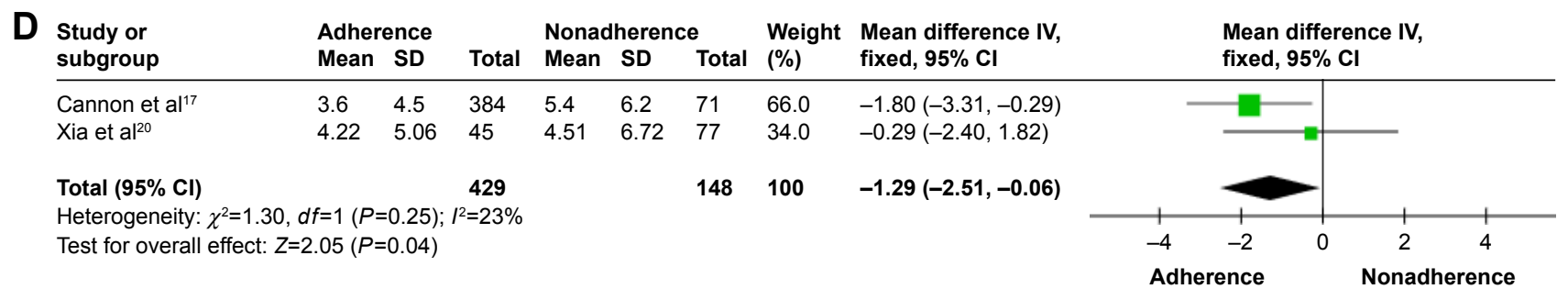

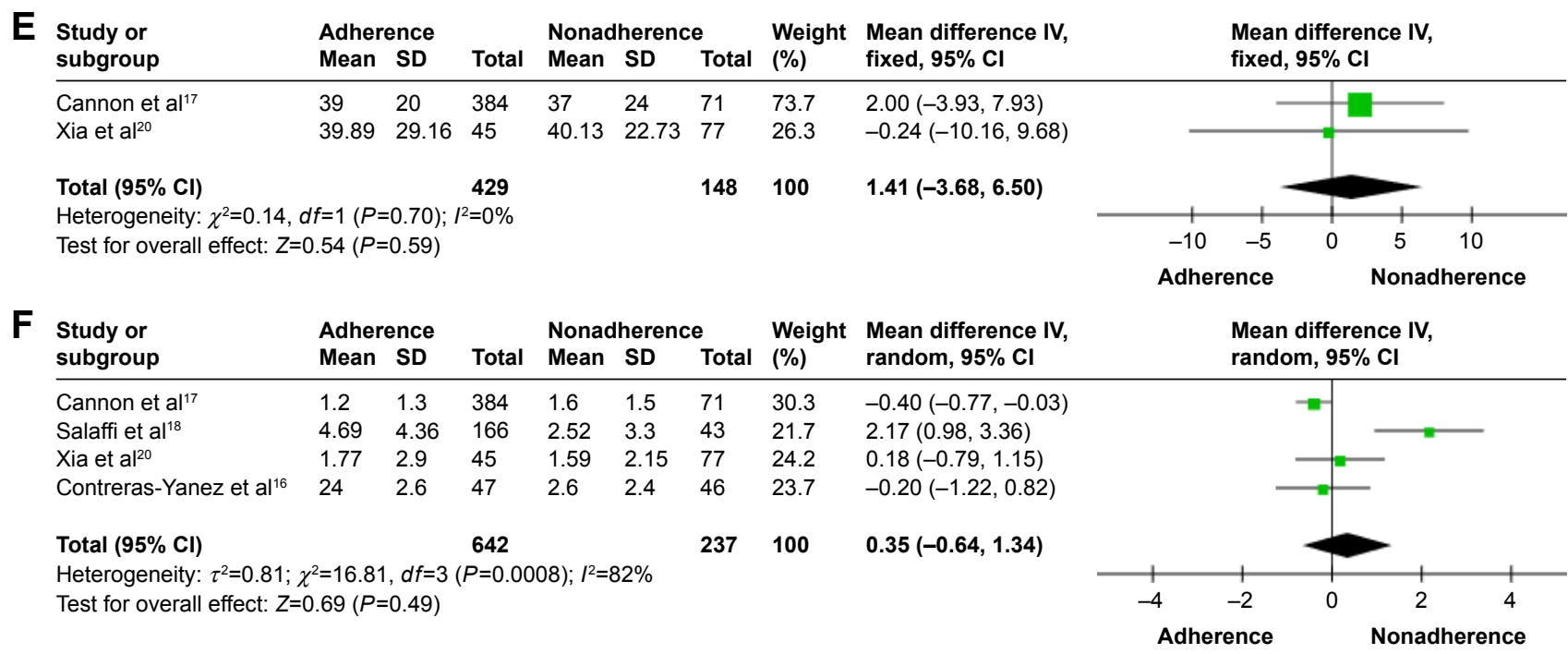

Figure 2 Forest plot of disease activity achievement in adherent patients versus nonadherent patients with RA.

Notes: (A) Total score of DAS-28 for RA; (B) ESR for RA; (C) SJC for RA; (D) TJC for RA; (E) VAS for RA; (F) CRP for RA.

Abbreviations: CRP, C-reactive protein; DAS-28, the 28-joint count disease activity score; $d f$, degrees of freedom; ESR, erythrocyte sedimentation rate; IV, independent variable; RA, rheumatoid arthritis; SJC, 28 swollen joint counts; TJC, 28 tender joint counts; VAS, visual analog scale. 
including a high disease activity, a satisfactory level of patient physician communication, increased knowledge of RA in general, age, and low numbers of comorbidity conditions. Furthermore, based on the information in the literature, the following possible aids to help with adherence were suggested: regular phone calls by specialized nurses, more explanation on why to take the medication, email messages or audio-automated computer messages, voice message as a refill reminder and other optional measures need to enter additional aids. ${ }^{18}$ Another study pointed that objective measures can better monitor medication adherence along with routine assessments of disease activity, and patient outcomes at the follow-up clinic visit. ${ }^{34}$

However, some potential limitations of this study should be noted. Firstly, the data were derived from studies that used different designs and involved different groups of patients (eg, from different countries), which might result in heterogeneity among the studies; as a consequence, random-effect analyses were used, resulting in wider CIs and relatively more weight being given to smaller studies. Secondly, we could not identify any significant sources of heterogeneity of outcomes. Although it was not possible to conclusively ascertain sources of heterogeneity, all results were confirmed in sensitivity analyses and no publication bias was found in our analyses.

\section{Conclusion}

Despite some limitations, the results of our study suggest that RA patients with higher medication adherence tended to have lower disease activity. It is certain that physicians can better help their patients with RA by improving their medication adherence with the treatment.

\section{Acknowledgments}

This study was supported by Grants from the Natural Science Foundation of China (Grant no 81401124); the Humanistic Nursing Care Foundation of China (Grant no RW2016AM14); Preventive Medicine Projects from Bureau of Jiangsu Province (Y2012083); “Top Six Types of Talents" Financial Assistance of Jiangsu Province (Grant no 10.WSN016); Jiangsu Provincial Commission of Health and Family Planning Foundation (Grant no Z201622); Science Foundation of Nantong City (Grant no MS22015003).

\section{Disclosure}

The authors report no conflicts of interest in this work.

\section{References}

1. Wong PK. Medication adherence in patients with rheumatoid arthritis: why do patients not take what we prescribe. Rheumatol Int. 2016; 36(11):1535-1542.
2. Lupoli R, Pizzicato P, Scalera A, et al. Impact of body weight on the achievement of minimal disease activity in patients with rheumatic diseases: a systematic review and meta-analysis. Arthritis Res Ther. 2016;18(1):297.

3. Richards JS, Cannon GW, Hayden CL, et al. Adherence with bisphosphonate therapy in US veterans with rheumatoid arthritis. Arthritis Care Res (Hoboken). 2012;64(12):1864-1870.

4. Jorgensen TS, Kristensen LE, Christensen R, et al. Effectiveness and drug adherence of biologic monotherapy in routine care of patients with rheumatoid arthritis: a cohort study of patients registered in the Danish biologics registry. Rheumatology (Oxford). 2015;54(12):2156-2165.

5. Joplin S, van der Zwan R, Joshua F, Wong PK. Medication adherence in patients with rheumatoid arthritis: the effect of patient education, health literacy, and musculoskeletal ultrasound. Biomed Res Int. 2015;2015:150658.

6. Pasma A, Schenk CV, Timman R, et al. Non-adherence to diseasemodifying antirheumatic drugs is associated with higher disease activity in early arthritis patients in the first year of the disease. Arthritis Res Ther. 2015;17(1):281.

7. Gadallah MA, Boulos DN, Gebrel A, Dewedar S, Morisky DE. Assessment of rheumatoid arthritis patients' adherence to treatment. Am JMed Sci. 2015;349(2):151-156.

8. Curtis JR, Bykerk VP, Aassi M, Schiff M. Adherence and persistence with methotrexate in rheumatoid arthritis: a systematic review. J Rheumatol. 2016;43(11):1997-2009.

9. Contreras-Yanez I, Pascual-Ramos V. Window of opportunity to achieve major outcomes in early rheumatoid arthritis patients: how persistence with therapy matters. Arthritis Res Ther. 2015;17:177.

10. Pasma A, Schenk C, Timman R, et al. Does non-adherence to DMARDs influence hospital-related healthcare costs for early arthritis in the first year of treatment? PLos One. 2017;12(2):e0171070.

11. Fransen J, van Riel PL. The disease activity score and the EULAR response criteria. Rheumatic Dis Clin North Am. 2009;35(4):745-757.

12. Sode J, Vogel U, Bank S, et al. Anti-TNF treatment response in rheumatoid arthritis patients is associated with genetic variation in the NLRP3-inflammasome. PLoS One. 2014;9(6):e100361.

13. Mjaavatten MD, Radner H, Yoshida K, et al. Do rheumatologists know best? An outcomes study of inconsistent users of diseasemodifying anti-rheumatic drugs. Semin Arthritis Rheum. 2015;44(4): 399-404.

14. Alemao E, Joo S, Kawabata H, et al. Effects of achieving target measures in rheumatoid arthritis on functional status, quality of life, and resource utilization: analysis of clinical practice data. Arthritis Care Res (Hoboken). 2016;68(3):308-317.

15. Arshad N, Ahmad NM, Saeed MA, Khan S, Batool S, Farman S. Adherence to methotrexate therapy in rheumatoid arthritis. PakJ Med Sci. 2016;32(2):413-417.

16. Contreras-Yanez I, Ponce DLS, Cabiedes J, Rull-Gabayet M, PascualRamos V. Inadequate therapy behavior is associated to disease flares in patients with rheumatoid arthritis who have achieved remission with disease-modifying antirheumatic drugs. Am J Med Sci. 2010; 340(4):282-290.

17. Cannon GW, Mikuls TR, Hayden CL, et al. Merging veterans affairs rheumatoid arthritis registry and pharmacy data to assess methotrexate adherence and disease activity in clinical practice. Arthritis Care Res. 2011;63(12):1680-1690.

18. Salaffi F, Carotti M, Di Carlo M, Farah S, Gutierrez M. Adherence to anti-tumor necrosis factor therapy administered subcutaneously and associated factors in patients with rheumatoid arthritis. J Clin Rheumatol. 2015;21(8):419-425.

19. Fransen J, Laan R, van der Laar M, Huizinga T, van Riel P. Influence of guideline adherence on outcome in a randomized controlled trial on the efficacy of methotrexate with folate supplementation in rheumatoid arthritis. Ann Rheum Dis. 2004;63(10):1222-1226.

20. Xia Y, Yin R, Fu T, et al. Treatment adherence to disease-modifying antirheumatic drugs in Chinese patients with rheumatoid arthritis. Patient Prefer Adherence. 2016;10:735-742. 
21. Moher D, Liberati A, Tetzlaff J, Altman DG. Reprint-preferred reporting items for systematic reviews and meta-analyzes: the PRISMA statement. Phys Ther. 2009;89(9):873-880.

22. Stroup DF, Berlin JA, Morton SC, et al. Meta-analysis of observational studies in epidemiology: a proposal for reporting. Meta-analysis Of Observational Studies in Epidemiology (MOOSE) group. JAMA. 2000;283(15):2008-2012.

23. Mata DA, Ramos MA, Bansal N, et al. Prevalence of depression and depressive symptoms among resident physicians: a systematic review and meta-analysis. JAMA. 2015;314(22):2373-2383.

24. Higgins JP, Thompson SG. Quantifying heterogeneity in a metaanalysis. Stat Med. 2002;21(11):1539-1558.

25. Thakkinstian A, McElduff P, D'Este C, Duffy D, Attia J. A method for meta-analysis of molecular association studies. Stat Med. 2005; 24(9):1291-1306.

26. Jeffrey C. Valentine TDPH. How many studies do you need a primer on statistical power for meta-analysis. J Edu Behav Stat. 2010; 35(2):215-247.

27. Blum MA, Koo D, Doshi JA. Measurement and rates of persistence with and adherence to biologics for rheumatoid arthritis: a systematic review. Clin Therapeutics. 2011;33(7):901-913.

28. DiMatteo MR GPLH. Patient adherence and medical treatment outcomes. Med Care. 2002;40:794-811.
29. Wabe N, Lee A, Wechalekar M, McWilliams L, Proudman S, Wiese M Adherence to combination DMARD therapy and treatment outcomes in rheumatoid arthritis: a longitudinal study of new and existing DMARD users. Rheumatol Int. 2017;37(6):897-904.

30. Bluett J, Morgan C, Thurston L, et al. Impact of inadequate adherence on response to subcutaneously administered anti-tumor necrosis factor drugs: results from the Biologics in Rheumatoid Arthritis Genetics and Genomics Study Syndicate cohort. Rheumatology. 2015; 54(3):494-499.

31. Markusse IM, Dirven L, Han KH, et al. Evaluating adherence to a treat-to-target protocol in recent-onset rheumatoid arthritis: reasons for compliance and hesitation. Arthritis Care Res. 2016;68(4):446-453.

32. Lee P, Tan LJ. Drug compliance in outpatients with rheumatoid arthritis. Aust N Z J Med. 1979;9(3):274-277.

33. Kumar K, Raza K, Gill P, Greenfield S. The impact of using musculoskeletal ultrasound imaging and other influencing factors on medication adherence in patients with rheumatoid arthritis: a qualitative study. Patient Prefer Adherence. 2016;10:1091-1100.

34. Jimmy B, Jose J. Patient medication adherence: measures in daily practice. Oman Med J. 2011;26(3):155-159. 


\section{Supplementary materials}

Table SI Summaries of measures for medication adherence and disease activity

\begin{tabular}{ll}
$\begin{array}{l}\text { First author, } \\
\text { year }\end{array}$ & Adherence methods \\
\hline $\begin{array}{l}\text { Fransen et al } \\
2004^{2}\end{array}$ & $\begin{array}{l}\text { Adherence was determined from the database, by comparing the } \\
\text { prescribed methotrexate (MTX) dose with the dose proposed by the } \\
\text { guidelines. If all MTX prescriptions for an individual patient were in } \\
\text { congruence with the guidelines, this was determined to be a case of full } \\
\text { adherence (FA). A case of non-adherence (NA) was determined if one } \\
\text { or more decisions were not in agreement with the guidelines. }\end{array}$
\end{tabular}

Yanez et al The CQ is a 20-items questionnaire (Appendix) that was locally $2010^{3}$ designed. A patient was considered to be CQ-adherent when boxes either 3 (Almost always) or 4 (Always) were filled for items 10 (In the past 2 months, I took my medication exactly at the day/s indicated by my rheumatologist), II (In the past 2 months, I took my medication exactly at the day/times indicated by my rheumatologist) and 12 (In the past 2 months, every time I took my medication, I took the precise number of tablets indicated by my rheumatologist). A patient was considered to be CQ-persistent if, in item 8 (In the past 2 months, how often did you completely stop taking your medication?), boxes 0 (Never) or I (Almost never) were filled. Patients were defined as adherent/persistent during the study period if scored as adherent/ persistent at the three consecutive evaluations.

The DRR is a standardized format that records names of actual (taken during the 7 days before the interview) DMARDs and their doses, timing and frequency. A patient was considered as DRR-adherent when the final percentage was $80 \%$ and DRR-persistent when taking any dose of the indicated DMARDs for at least 5 consecutive days of the 7 days.

Cannon et al For each patient, the medication possession ratio (MPR) was calculated $20 \mathrm{II}^{4}$ for the first episode of MTX exposure of a duration of $>12$ weeks for both new and established MTX users. High MTX adherence was defined as an MPR $>0.80$ and low MTX adherence was defined as an $\operatorname{MPR}<0.80$.

Richards et al Medication adherence was assessed by calculating the medication $2012^{5}$ possession ratio (MPR), defined as the proportion of treatment time that a patient had an available drug. Therefore, for this analysis, subjects were deemed adherent with bisphosphonate therapy if the MPR was $\geq 0.80$ and non-adherent if the MPR was $<0.80$

Salaffi et al At baseline, all eligible patients underwent clinical rheumatologic visit in $2015^{6}$ order to acquire data of the disease activity, and determine the biological treatment. After 12 months, we sent the MMAS- 4 to the patients to complete, by home address or Internet electronic system (according their comfort). For those with scarce confidence with the Internet, the MMAS-4 was sent by regular mail, whereas for those who chose the Internet system, a telemedical care called "REmote TElemonitoring for MAnaging Rheumatologic Condition and HEalthcare programmes (RETEMARCHE)" was used. Responses to the MMAS-4 questions are indicated in binary fashion (yes/no). The degree of adherence was determined according to the score resulting from the sum of all the correct answers: high adherence ( 0 points), average adherence ( $\mathrm{I}-2$ points), and poor adherence (3-4 points). Higher scores indicate less adherence.

Disease activity methods

The disease activity score (DAS) was calculated using the Ritchie articular index (RAI), a swollen joint count, erythrocyte sedimentation rate (ESR), and general health. The RAI was calculated according to the grading and accumulation described by Ritchie et al,' and ranged from 0 to 78.8. The swollen joint count ranged from 0 to 44 . General health $(\mathrm{GH})$ and pain were rated on $100 \mathrm{~mm}$ visual analog scale (VAS).

The primary outcome variable was the DAS-28, ESR and C-reactive protein (CRP).

The primary outcome variable was the DAS-28, Secondary outcome variables evaluated were tender joint count, swollen joint count, patient global disease assessment (100 mm scale), patient pain (10-point scale), physician global disease assessment (100 mm scale), Multidimensional Health Assessment Questionnaire, ESR, and CRP level.

Disease activity as measured by the mean Disease Activity Score in 28 joints (DAS-28).

CDAl, ESR, CRP, SJC, TJC

Clinical Disease Activity Index is the only composite index that does not incorporate an acute phase response and can therefore be used to conduct a disease activity evaluation essentially anytime and anywhere. Clinical Disease Activity Index ranges from 0 (totally inactive disease) to 76 (very active disease). Patients can be divided into those at low (CDAI $\leq 10)$, moderate (CDAI $\leq 22)$, and high disease activity (CDAI $>22$ ). Clinical Disease Activity Index of 2.8 or less corresponds to remission. 
Table SI (Continued)

\begin{tabular}{|c|c|c|}
\hline $\begin{array}{l}\text { First author, } \\
\text { year }\end{array}$ & Adherence methods & Disease activity methods \\
\hline $\begin{array}{l}\text { Arshad et al } \\
2016^{7}\end{array}$ & $\begin{array}{l}\text { Adherence was defined as omission of two or less doses of prescribed } \\
\text { MTX during the previous } 8 \text { weeks. This number was used because two } \\
\text { times or less would represent adherence rate of } 80 \% \text { or more which is } \\
\text { considered acceptable by most authors. Patients who missed three or } \\
\text { more doses were considered nonadherent. }\end{array}$ & $\begin{array}{l}\text { Disease activity on the current visit was calculated by } \\
\text { DAS- } 28 \text { which has four variables; tender joint count, } \\
\text { swollen joint count, patient pain VAS and ESR. }\end{array}$ \\
\hline $\begin{array}{l}\text { Xia et al } \\
2016^{8}\end{array}$ & $\begin{array}{l}\text { Adherence was assessed using the CQR. The CQR is a I9-item, } \\
\text { self-administered questionnaire, and was developed to correctly } \\
\text { identify patients who were classified as "low" adherers (taking, } \\
80 \% \text { of their medication correctly). The questions were identified } \\
\text { through focus groups and clinician's expert opinion of the likely } \\
\text { hindrances to medication taking. The } 4 \text {-point Likert answering scale } \\
\text { ranges from "Definitely don't agree" (scored I) to "Definitely agree" } \\
\text { (scored 4); items } 4,8,9,1 \text { I, I2, and I9 have to be reversely recoded } \\
(4=I, 3=2 \text {, etc). Lower scores indicate lower levels of adherence. }\end{array}$ & $\begin{array}{l}\text { Disease activity was estimated with the valid and } \\
\text { reliable DAS-28, incorporating } 28 \text { swollen and tender } \\
\text { joint counts, patient's assessment of disease activity } \\
(0-100 \text { mm VAS, where } 0=\text { not active at all and } \\
100=\text { extremely active), erythrocyte sedimentation rate } \\
(\mathrm{mm} / \text { hour), and CRP ( } \mathrm{mg} / \mathrm{L}) \text {. The questionnaire was also } \\
\text { used to collect concurrent information about disease- } \\
\text { related data and general health perception rated on VAS. }\end{array}$ \\
\hline
\end{tabular}

Abbreviations: CQ, compliance Questionnaire; DRR, drug record registry; MPR, medication possession ratio; MMAS-4 the original 4-item, Morisky Medication Adherence Scale; CQR, Compliance Questionnaire on Rheumatology; ESR, erythrocyte sedimentation rate; DAS-28, 28-joint count disease activity score; CDAI, Clinical Disease Activity Index; SJC, 28 swollen joint counts; TJC, 28 tender joint counts.

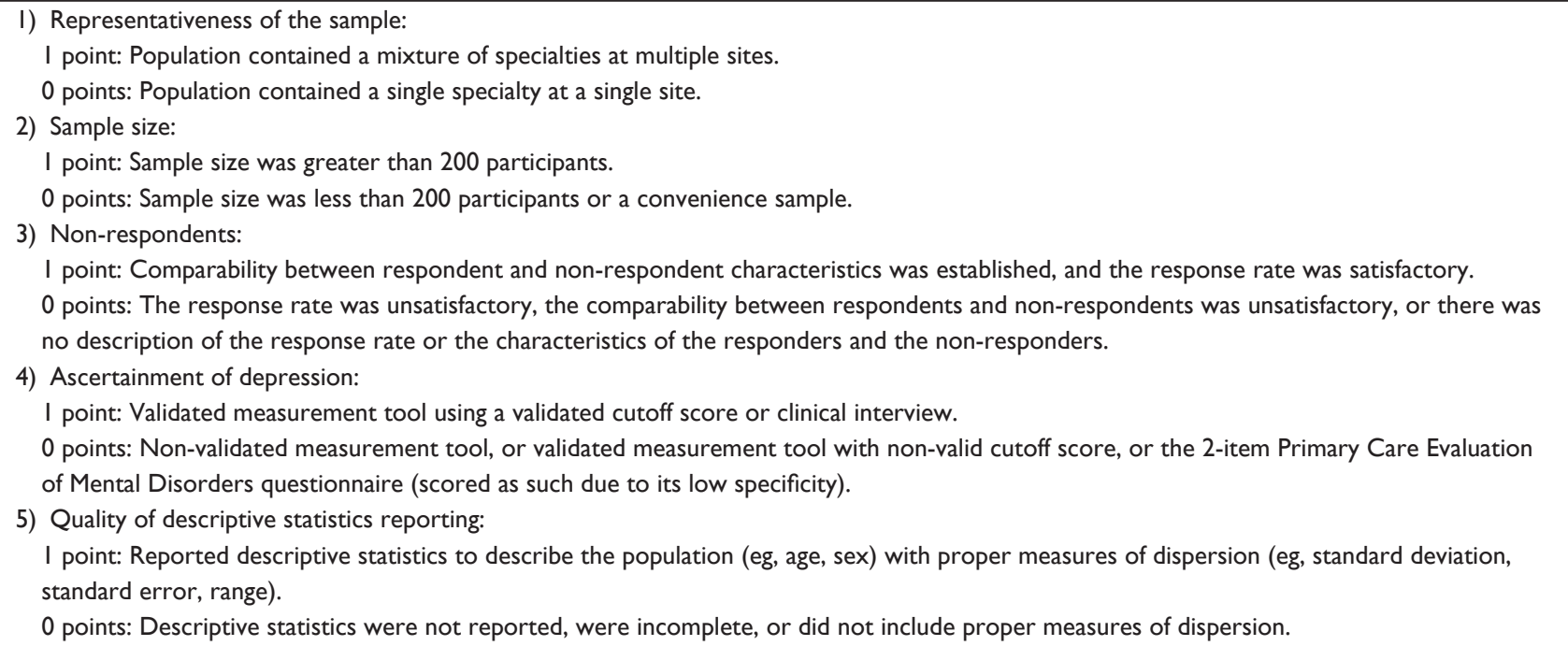

Box SI Quality assessment Modified Newcastle-Ottawa scoring guide.

Notes: This scale, the scoring of which ranges from 0 to 5 , assesses quality in several domains: sample representativeness and size, comparability between respondents and non-respondents, ascertainment of depressive symptoms, and statistical quality. Studies were judged to be of low risk of bias ( $\geq 3$ points) or high risk of bias ( $<3$ points). 


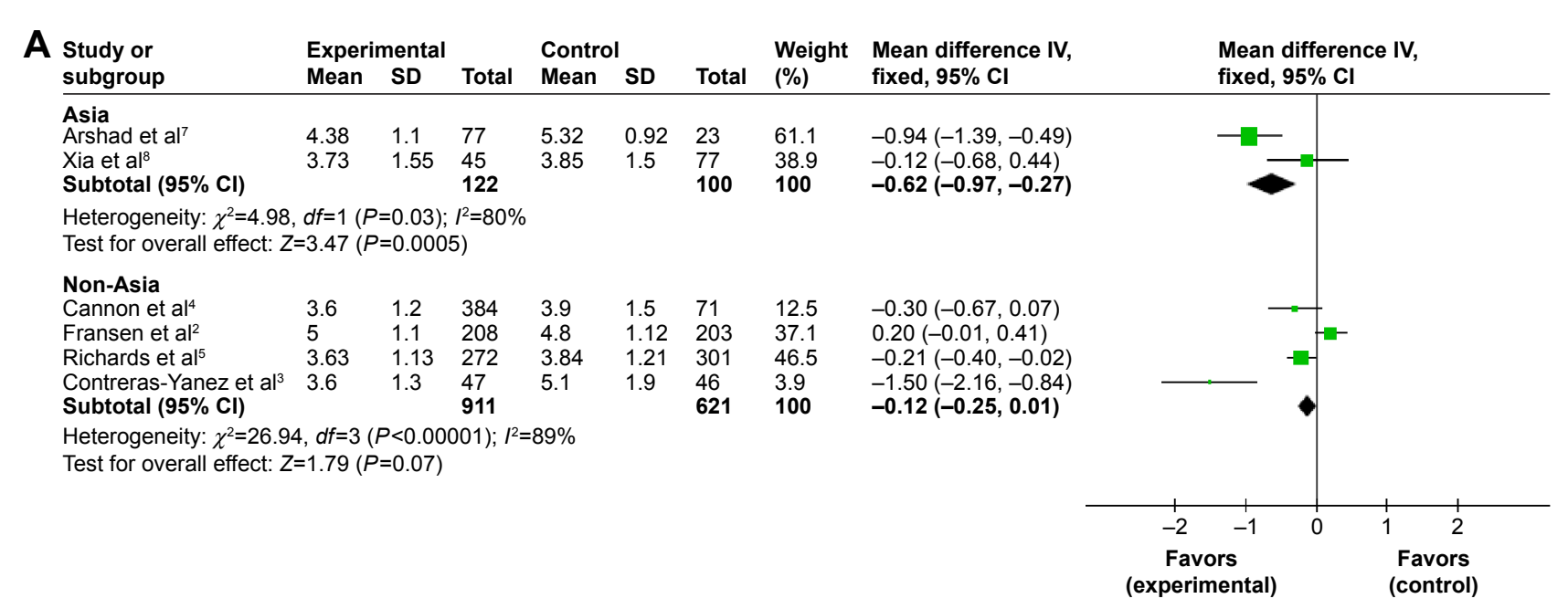

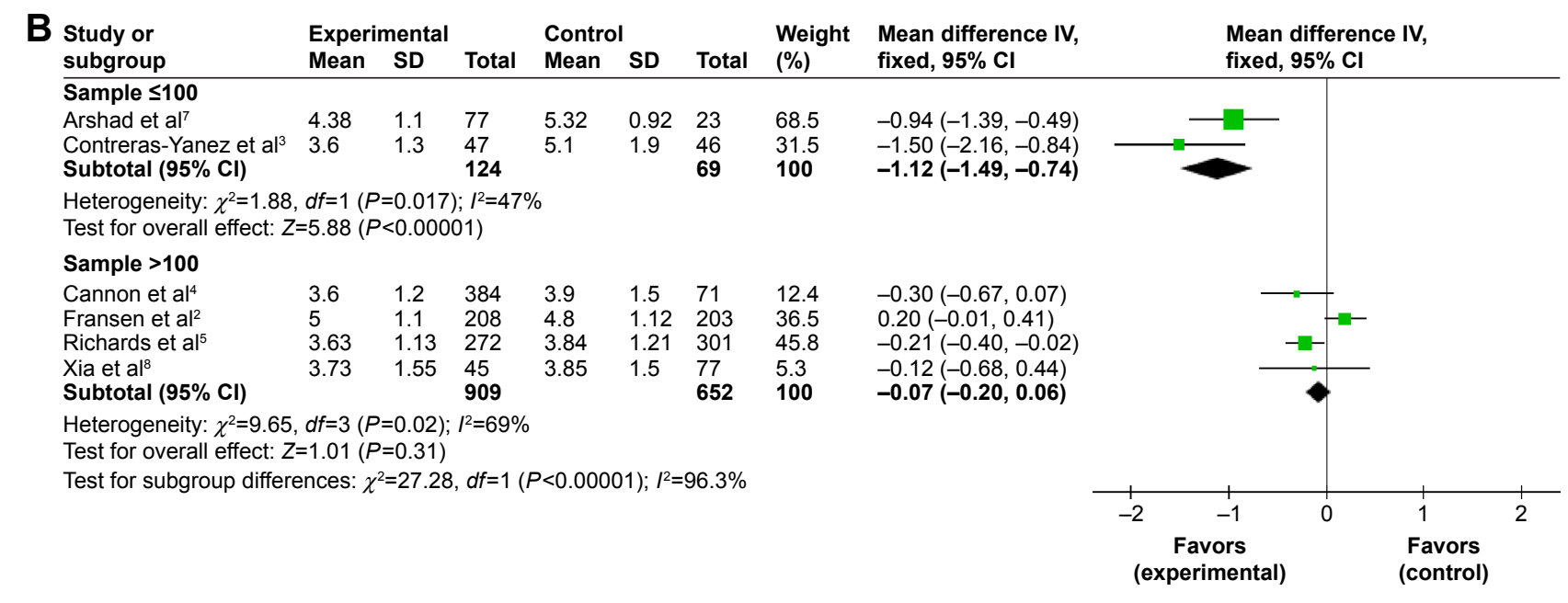

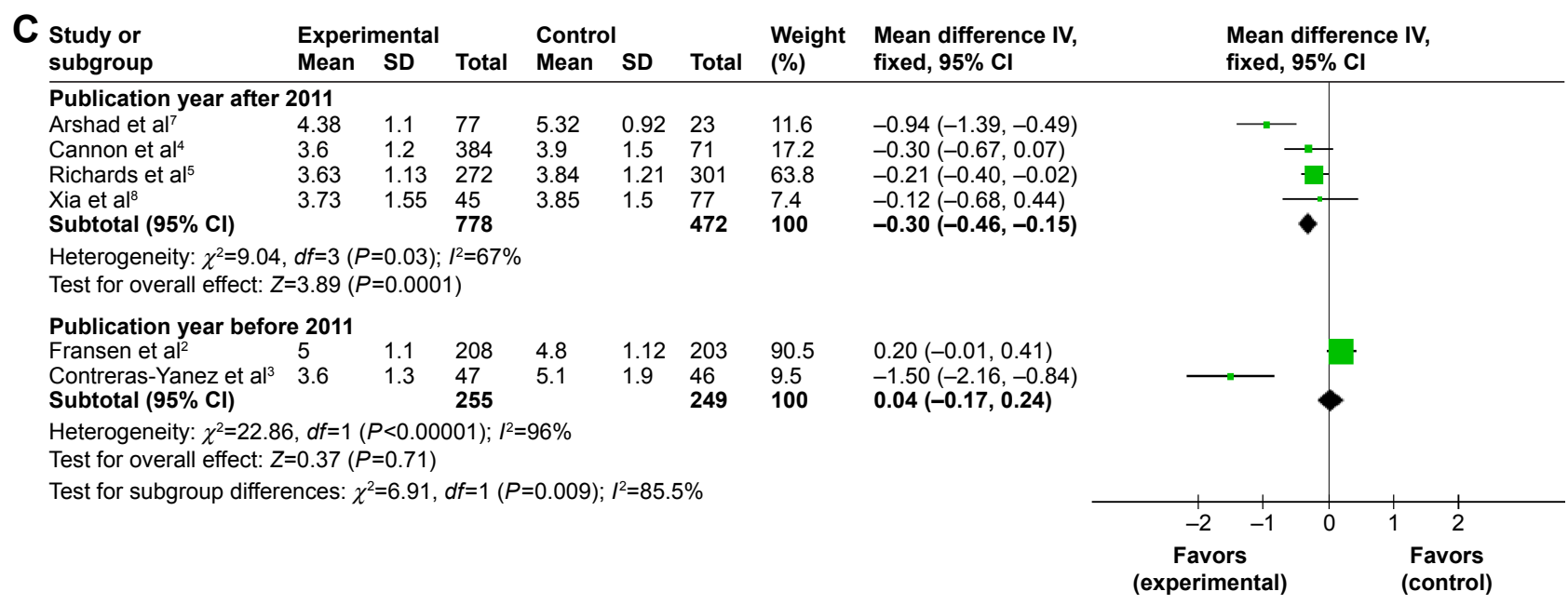

Figure SI (Continued) 


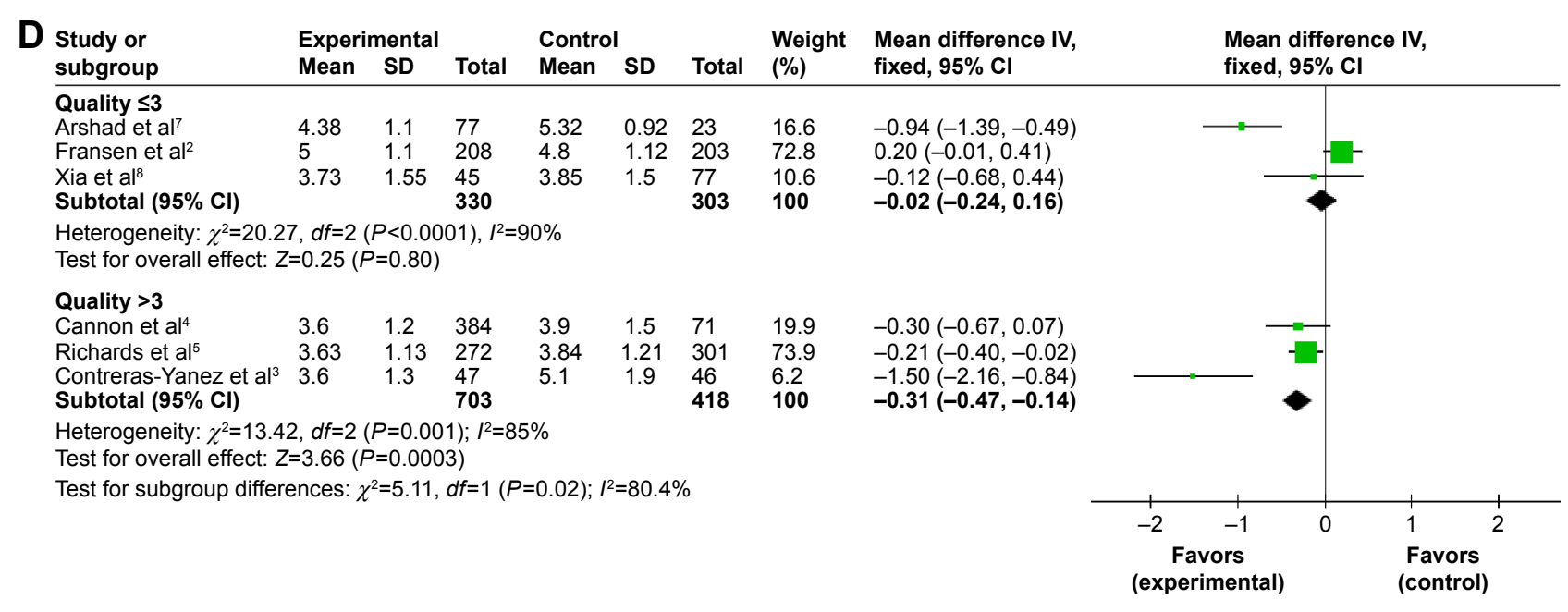

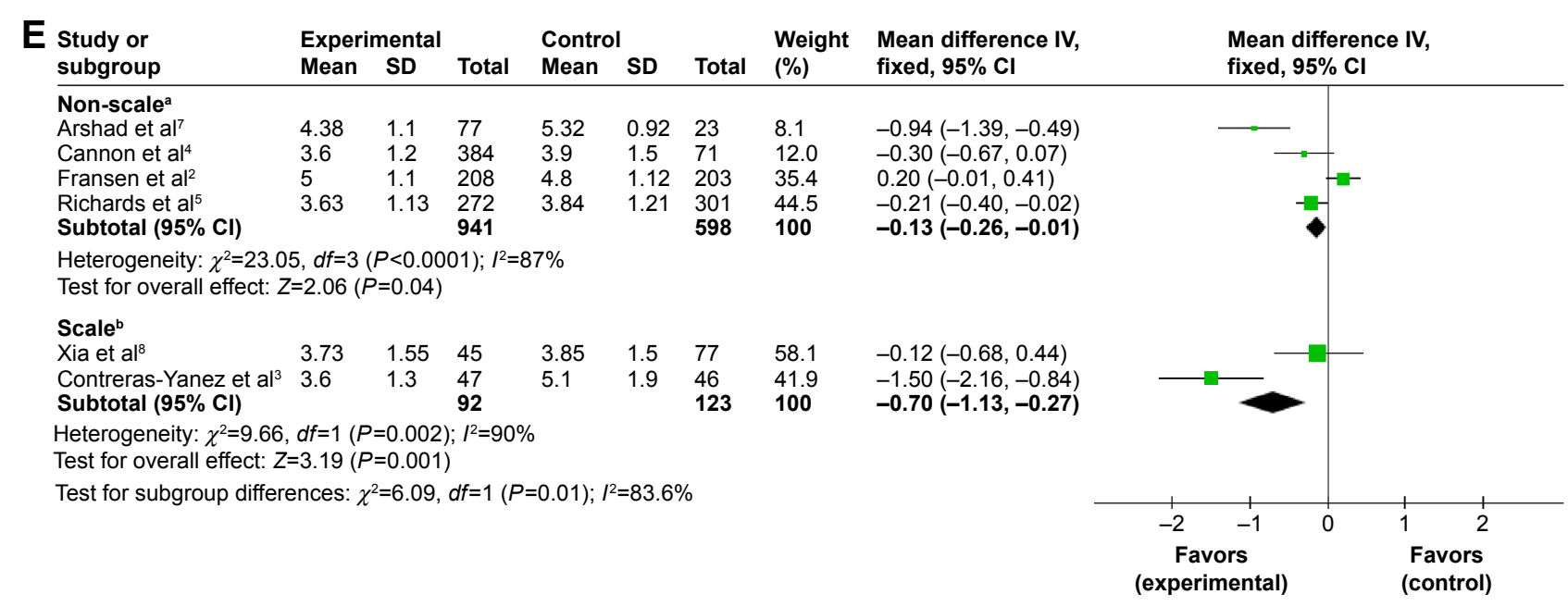

Figure SI Summary of subgroup analysis.

Notes: (A) Subgroup analysis of country. (B) Subgroup analysis of sample size. (C) Subgroup analysis of publication year. (D) Subgroup analysis of study quality. (E) Subgroup analysis of the measurements of medication adherence. ${ }^{a}$ Not use scale to measure medication adherence completely, bonly use scale to measure medication adherence. Abbreviations: IV, independent variable; $d f$, degrees of freedom.

\section{References}

1. Ritchie DM, Boyle JA, McInnes JM, et al. Clinical studies with an articular index for the assessment of joint tenderness in patients with rheumatoid arthritis. Q J Med. 1968;37(147):393-406.

2. Fransen J, Laan R, van der Laar M, Huizinga T, van Riel P. Influence of guideline adherence on outcome in a randomized controlled trial on the efficacy of methotrexate with folate supplementation in rheumatoid arthritis. Ann Rheum Dis. 2004;63(10):1222-1226.

3. Contreras-Yanez I, Ponce DLS, Cabiedes J, Rull-Gabayet M, PascualRamos V. Inadequate therapy behavior is associated to disease flares in patients with rheumatoid arthritis who have achieved remission with disease-modifying antirheumatic drugs. Am J Med Sci. 2010;340(4):282-290.

4. Cannon GW, Mikuls TR, Hayden CL, et al. Merging veterans affairs rheumatoid arthritis registry and pharmacy data to assess methotrexate adherence and disease activity in clinical practice. Arthritis Care Res. 2011;63(12):1680-1690.
5. Richards JS, Cannon GW, Hayden CL, et al. Adherence with bisphosphonate therapy in US veterans with rheumatoid arthritis. Arthritis Care Res (Hoboken). 2012;64(12):1864-1870.

6. Salaffi F, Carotti M, Di Carlo M, Farah S, Gutierrez M. Adherence to anti-tumor necrosis factor therapy administered subcutaneously and associated factors in patients with rheumatoid arthritis. J Clin Rheumatol. 2015;21(8):419-425.

7. Arshad N, Ahmad NM, Saeed MA, Khan S, Batool S, Farman S. Adherence to methotrexate therapy in rheumatoid arthritis. Pak J Med Sci. 2016;32(2):413-417.

8. Xia Y, Yin R, Fu T, et al. Treatment adherence to disease-modifying antirheumatic drugs in Chinese patients with rheumatoid arthritis. Patient Prefer Adherence. 2016;10:735-742. 


\section{Publish your work in this journal}

Patient Preference and Adherence is an international, peer-reviewed, open access journal that focuses on the growing importance of patient preference and adherence throughout the therapeutic continuum. Patient satisfaction, acceptability, quality of life, compliance, persistence and their role in developing new therapeutic modalities and compounds to optimize clinical outcomes for existing disease states are major areas of interest for the journal. This journal has been accepted for indexing on PubMed Central. The manuscript management system is completely online and includes a very quick and fair peer-review system, which is all easy to use. Visit http://www. dovepress.com/testimonials.php to read real quotes from published authors.

Submit your manuscript here: http://www.dovepress.com/patient-preference-and-adherence-journal 